\title{
EFFECT OF INCLINED HUMP ON THE TURBULENCE INTENSITIES AND FLOW CHARACTERISTICS IN THE SEPARATED FLOW THROUGH WATER STRUCTURES
}

\author{
Mahmoud.I.A.Elshewey \\ Associate Professor, Water\& Water Structures Engg., Dept. Faculty of Engg. Zagazig University, Zagazig, Egypt, \\ m.elshewey@yahoo.com
}

\begin{abstract}
In this paper, an experimental study was carried out to investigate the turbulence field and flow characteristics in the separated flow through inclined hump in water structures in rectangular channel using Laser. To study the variation of the turbulence, energy loss, relative energy (efficiency) and relative depth with main parameters affecting the inclined hump These parameters include the hump angle, relative height, upstream Froude number, bottom slope. Non-dimensional design curves are provided to relate the turbulence intensities and flow characteristics. The results show that, the variation of the energy loss increases till of hump angle about $45^{\circ}$. This rate of increase decreases about this value of angle of hump. The energy loss increases with the increasing of bed slope and relative height. The energy loss is quite high at a relative contraction of 0.3 . Also, the results clearly showed the dependence of the hump inclination angle on the turbulence intensities. For hump angle $\geq 20^{\circ}$, the turbulence intensity in the separation zones was growing with increasing hump angles and the maximum was observed for hump inclination angles between $20^{\circ}$ and $30^{\circ}$. The results indicated that, the most significant differences in flow structures occurred with hump angle less than $45^{\circ}$.
\end{abstract}

Keywords: Energy loss-Turbulence intensities-Water structures- Hump-Laser Technique-Hump angle-Bottom slopeRelative height-Relative depth-Froude number-separation zones. $* * *$

\section{INTRODUCTION}

In the design of hydraulic structures, designers do their best to avoid sudden transition of the flow by sudden transitions to ensure smooth flow with minimum energy loss and reduced turbulence patterns. Open channel transition are commonly used in hydraulic structures in variety of situation to serve as link with minimum possible energy loss. Since these transitions are meant for continuous use, their role in minimization of the energy loss and attenuation of turbulence assumes significance. The flow through the contracted section may be critical, subcritical or supercritical with subcritical flow upstream. The change in the cross section disturbs the flow in the contracted reach and near to it from both upstream and downstream. The change in the channel cross section, slope, and/or alignment over a specified reach is termed local transition. Such channel transition are used mainly to avoid or minimize the excessive energy loss, to eliminate the cross waves, the resulting turbulence and to ensure safety of both the structure and the downstream channel reach. The information regarding the turbulence characteristics in the transitional structures is somewhat scanty. Paradoxically enough, the problem of separation of the main stream of flow at open channel transitions or at an abrupt change of the boundary attracted the attention of investigators since the earliest time and yet it remains one of the least understood and the most critical problem of fluid dynamics today. Open channel transitions have been studied extensively because of their use in water resources engineering and their efficacy in reducing the energy loss in hydraulic structures. Transitions are provided, whenever the size or the shape of the cross section of an open channel changes. Such changes are often required in natural and artificial channel for water structures economically as well as for practical reasons. The transitions may be vertical or horizontal, contracting or expanding, sudden or gradually which are required for subcritical or supercritical flows. Thus the transition on the flow depends mainly of the boundary geometry, the discharge and the state of flow. The phenomenon is usually so complicated that the resulting flow pattern is not readily subjected to any analytical solution. So, a practical solution is possible, however, through experimental investigation. The present research deals only with vertical transitions through inclined hump. Studies on channel transitions and design of flume inlets include those of Attia [2], Nandana [14] and Vitta [19]. Formica [6] tested experimentally the various design for channel transition. The main results of Formica were reported in Chow [4]. The turbulent flow models in open channel flows were discussed by Garde [7], Rodi [16], Nezu and Nakagawa [12]. Experimental investigation on turbulent structure of back facing step flow, have been reported by several investigators $[1,8,13,15]$. Measurements of 
turbulence characteristics in open channel flows using LDA have been pointed by several investigators $[3,5,9,10,11]$.

In the present investigation, the main objective is to study the effect of the inclined hump on the turbulence and flow characteristics in the separated flow through water structures using laser technique in sloping rectangular open channel. Also, to assess the influence of hump angle, bottom slope, relative height, relative depth and upstream Froude number on the stream wise and vertical turbulence intensity components, stream wise and vertical mean velocity components, turbulence shear stress, energy losses and efficiency.

\section{EXPERIMENTAL SET UP AND PROCEDURE:}

The experiments were conducted in a tilting glass sided flume $4 \mathrm{~m}$ long, $10 \mathrm{~cm}$ wide and $30 \mathrm{~cm}$ deep as shown in Fig.1. The discharge was measured using a pre-calibrated orifice meter. An in-line valve fitted into the main supplying pipeline was used to regulate the flow rate. Depth measurements were taken using a needle point gauge with a reading accuracy of \pm 0.1 $\mathrm{mm}$. Uniform flow conditions were reached using a carefully designed inlet tank. The slope was adjusted using a screw jack located at the upstream end of the flume while at the downstream end, the flume is allowed to rotate freely about a hinged pivot. The slope was directly determined using slope indicator. A downstream adjustable gate was used to regulate the tail water surface elevation. The experiments were carried out using five different relative heights, $\mathrm{h} / \mathrm{b}$ of $0.1,0.2,0.3,0.4$, 0.5 and 0.6. Six different hump slopes, $S_{0}$, of 0.0 0.005, 0.01, $0.015,0.02$, and 0.025 . Also, six different hump angles $\theta$ of $15^{\circ}, 30^{\circ}, 45^{\circ}, 60^{\circ}, 75^{\circ}$ and $90^{\circ}$ were used to illustrate the flows formed in sloping hump. The slopes were selected based on the flume facilities. For each combination of upstream Froude number $\mathrm{F}_{\mathrm{u}}$, hump slope, hump angle and relative height, five different flow rates ranging from $400 \mathrm{~L} / \mathrm{min}$ to $250 \mathrm{~L} / \mathrm{min}$ were used. The upstream control gate was so adjusted to produce supercritical depth, $\mathrm{y}_{\mathrm{u}}$. The downstream adjustable gate was adjusted to control the tailwater depth, $y_{d}$. For each combination of hump slope, hump angle and relative height, the flow rate, the depth depths upstream and downstream the hump were measured.

\section{LASER MEASURING TECHNIQUE:}

The experimental data were collected using a DANTEC two color back-scatter mode, two Burst Spectrum Analyzers [BSA] were used to evaluate the Doppler frequencies, and subsequent computer analysis consisted of velocity bias averaging and rejection. Figure. 2 shows a block diagram of the two component LDV set up used for the measurements. On a traverse bench, the measuring probe [laser beams or measuring volume] was focused on a measuring a point from one side of the channel glass wall through an optical lens. The number of sample taken at every point was 4000 bursts. This curves point to a simple averaging time of about 100 seconds. The data rate was about 10-20 Hz. Before acquiring the data, the LDV signal was checked for its regular Doppler burst that correspond to a particle passing through the measuring volume. The measuring were taken at different positions along the centerline upstream, within and downstream of the hump. Fig. 3 shows the location of measuring sections $[\mathrm{x} / \mathrm{b}]$.

\section{THEORETICAL STUDY}

Figure 3 shows a definition sketch of flow through the inclined hump in sloping rectangular channel. The variables affecting the flow through the inclined hump are shown on the figure and explained at the notation section. The functional relationship of the energy loss $(\Delta \mathrm{E})$ through the inclined hump could be written as follows:

$$
f_{1}\left[\mathrm{~g}, \mathrm{Y}_{\mathrm{u}}, \mathrm{V}_{\mathrm{u}}, \mathrm{Y}_{\mathrm{d}}, \mathrm{h}, \mathrm{b}_{\mathrm{u}}, \mathrm{b}_{\mathrm{d}}, \Delta \mathrm{E}, \mathrm{S}_{\mathrm{o}}, \theta\right]
$$

Using the dimensional analysis $\left(b_{u}=b_{d}=b\right)$, the following dimensionless relationship is obtained:

$$
\frac{\Delta \mathrm{E}}{\mathrm{Y}_{u}}=f_{2}\left[\mathrm{~F}_{u}, \frac{\mathrm{Y}_{\mathrm{d}}}{\mathrm{Y}_{\mathrm{u}}}, \frac{\mathrm{b}}{\mathrm{Y}_{u}}, \frac{\mathrm{b}}{\mathrm{Y}_{u}}, S_{o}, \theta\right]
$$

It may be appear better to analyze the energy loss through the inclined hump as a ratio related to the upstream energy, $\mathrm{E}_{\mathrm{u}}$. Therefore, $E_{u}$ was used instead of upstream depth $Y_{u}$ in the left hand side of equation (2), which become:

$$
\frac{\Delta \mathrm{E}}{\mathrm{E}_{u}}=f_{3}\left[\mathrm{~F}_{u}, \frac{\mathrm{h}}{\mathrm{b}}, S_{o}, \theta\right]
$$

in which $\mathrm{V}$ is velocity at the point of the flow depth $\mathrm{Y}, \mathrm{b}$ channel width $\mathrm{u}$ for just upstream the hump and $\mathrm{d}$ just downstream of the hump.

Also, from continuity equation

$$
F_{u}{ }^{2}=\left(\mathrm{b}_{d} / \mathrm{b}_{u}\right)^{2}\left(\mathrm{Y}_{d} / \mathrm{Y}_{u}\right)^{3} \mathrm{~F}_{d}^{2}
$$

The above equation represents the relationship between $F_{u}, F_{d}$ and $\mathrm{Y}_{\mathrm{d}} / \mathrm{Y}_{\mathrm{u}}$ as parameters.

The energy loss is computed using the following expression:

$$
\mathrm{Y}_{u}+\mathrm{Q}^{2} / 2 g b u^{2} \mathrm{Y}_{u}{ }^{2}=Y d+\mathrm{Q}^{2} / 2 g b d^{2} \mathrm{Y}_{d}{ }^{2}+h+\Delta \mathrm{E}
$$

Equation (5) may be rearranged to

$$
\mathrm{Y}_{u}+\mathrm{Y}_{u} \cdot \mathrm{F}_{u}^{2} / 2=\mathrm{Y}_{d}+\mathrm{Y}_{d} \cdot \mathrm{F}_{d}^{2} / 2+h+\Delta \mathrm{E}
$$

Hence,

$$
\mathrm{Y}_{u}\left(1+\mathrm{F}_{u}^{2} / 2\right)=\mathrm{Y}_{d}\left(1+\mathrm{F}_{d}^{2} / 2\right)+h+\Delta \mathrm{E}
$$

From equations (4) and (7), equation may be rearranged as: 


$$
\begin{gathered}
\left.\mathrm{F}_{u}{ }^{2}=2\left[\mathrm{Y}_{d} / \mathrm{Y}_{u}-1\right)+\Delta \mathrm{E} / \mathrm{Y}_{u}+h / \mathrm{Y}_{u}\right] /[1- \\
\left.1 /\left(\mathrm{b}_{d .} \mathrm{Y}_{d} / \mathrm{b}_{u .} \mathrm{Y}_{u}\right)^{2}\right]
\end{gathered}
$$

The above equation represents the relationship between $F_{u}$, $\mathrm{Y}_{\mathrm{d}} / \mathrm{Y}_{\mathrm{u}}$ and $\Delta \mathrm{E} / \mathrm{Y}_{\mathrm{u}}$ as parameters.

Again, Equation (5) could be written as follows $\left(b=b_{u}=b_{d}\right)$ :

$$
\begin{aligned}
& \Delta \mathrm{E} / \mathrm{E}_{u}=\mathrm{Y}_{u} / \mathrm{E}_{u}\left[\left(1+\mathrm{F}_{u}{ }^{2} / 2\right)-\mathrm{Y}_{d} / \mathrm{Y}_{u}-h / \mathrm{Y}_{u}+\right. \\
& \left.\mathrm{F}_{u}{ }^{2} / 2\left(\mathrm{Y}_{d} / \mathrm{Y}_{u}\right)^{2}\right]
\end{aligned}
$$

The above equation represents the relationship between the efficiency

$$
\left(\mathrm{E}_{d} / \mathrm{E}_{u}=1-\Delta \mathrm{E} / \mathrm{E}_{u}\right), \Delta \mathrm{E} / \mathrm{E}_{u}, \mathrm{Y}_{d} / \mathrm{Y}_{u}, \mathrm{~F}_{u}
$$

as dimensionless parameters.

\section{Where;}

$E_{u}$ and $E_{d}$, specific energies upstream and downstream the hump respectively; $F_{u}$ and $F_{d}$ Froude numbers upstream and downstream the hump respectively; $\mathrm{Y}_{\mathrm{u}}$ and $\mathrm{Y}_{\mathrm{d}}$ water depths upstream and downstream the hump respectively; $b_{u}$ and $b_{d}$ upstream and downstream widths respectively; h hump height; $\theta$ hump angle; $S_{0}$ bed slope; $b$ hump width; and the energy $\operatorname{loss}(\Delta \mathrm{E})$

\section{RESULTS AND DISCUSSION}

The relative energy loss with regard to the energy upstream of the inclined hump $\Delta \mathrm{E} / \mathrm{E}_{\mathrm{u}}$ is plotted as a function of hump angle $\theta$ of $15^{\circ}, 30^{\circ}, 45^{\circ}, 60^{\circ}, 75^{\circ}$ and $90^{\circ}$ for various relative heights $\mathrm{h} / \mathrm{b}$, at different bottom slopes. Fig.4 shows the variation of the hump angle $\theta$ with the relative energy loss $\Delta \mathrm{E} / \mathrm{E}_{\mathrm{u}}$ for relative heights $\mathrm{h} / \mathrm{b}=0.1,0.2,0.3,0.4,0.5$ and 0.6 at different bed slopes of 0.0, 0.01, 0.02 and 0.025 . From this figure, it can be observed that for a fixed $S_{0}$, the trend of variation between $\theta$ and $\Delta \mathrm{E} / \mathrm{E}_{\mathrm{u}}$ increases as the relative heights increases. The energy loss is the least value for relative height $h / b$ of 0.1 and a maximum value for relative height $\mathrm{h} / \mathrm{b}$ of 0.6 . The variation of the energy loss increases till f hump angle about $45^{\circ}$. This rate $\mathrm{f}$ increase decreases about this value of angle of hump. The energy loss is relatively small up to the relative height $h / b$ of 0.3. The rate of increase in energy loss, Fig4, is almost the same between the relative height 0.1 and 0.2 , and 0.2 and 0.3 , it has the double value between 0.4 to 0.5 and almost six folds between 0.5 and 0.6 as compared to the increase in loss between the relative height ratio 0.1 to 0.2 . The trend is almost the same for all other relative heights. Also, as the angle of hump $\theta$ increases up to $45^{\circ}$ the rate of increase in the energy loss $\Delta \mathrm{E} / \mathrm{E}_{\mathrm{u}}$ is relatively high for all the relative heights $\mathrm{h} / \mathrm{b}$, being very high for the relative height $h / b$ of 0.6 . Above $\theta=45^{\circ}$, the increase in the energy loss is much slower particularly for $\theta$ greater than $45^{\circ}$ at which the energy loss is almost constant for all practical purpose. This figure indicates that, the slope has a remarkable effect on the energy loss. With increasing bed slope, the energy loss is increase.

Figure 5 depicts the variation of upstream Froude number $F_{u}$ with relative energy loss $\Delta \mathrm{E} / \mathrm{E}_{\mathrm{u}}$ for different relative heights of $0.1,0.2,0.3,0.4,0.6$ and 0.6 for different bottom slopes $S_{0}$ of $0.0,0.01,0.02$ and 0.025 respectively at a fixed hump angle $\theta=15^{\circ}$. The relationship between $F_{u}$ and $\Delta E / E_{u}$ is family of curves which are similar hyperbolas of a higher order according to Equation [5]. It can be shown that, from this figure, with the same value of bed slope, the value of $\Delta \mathrm{E} / \mathrm{E}_{\mathrm{u}}$ increases with the increasing value of $F_{u}$. Also, with the same value of $F_{u}$, the value of $\Delta \mathrm{E} / \mathrm{E}_{\mathrm{u}}$ increases with the increasing value of $\mathrm{F}_{\mathrm{u}}$. Also, with the same value of $F_{u}$, the value of $\Delta E / E_{u}$ increases with the increasing value of $\mathrm{h} / \mathrm{b}$. Also, it is observed that an extension of the lower sides of the curves through the point $\left(\mathrm{F}_{\mathrm{u}}=0, \Delta \mathrm{E} / \mathrm{E}_{\mathrm{u}}=0\right)$ gives hydrostatic case. The variation of bed slope $S_{0}$ with $\Delta E / E_{u}$ for different relative heights $\mathrm{h} / \mathrm{b}$ are presented in Fig.6 for hump angle $\theta$ of $15^{\circ}, 30^{\circ}, 45^{\circ}$, and $90^{\circ}$ respectively. From this figure, it can observed that for a fixed $\theta$, the trend of variation between $\mathrm{S}_{\mathrm{o}}$ and $\Delta \mathrm{E} / \mathrm{E}_{\mathrm{u}}$ is increasing with approximately linear trend. Also, at a particular $S_{0}, \Delta E / E_{u}$ increases as the relative height $\mathrm{h} / \mathrm{b}$ increases. This figure indicates that the bottom slope $\mathrm{S}_{\mathrm{o}}$ has a remarkable effect on the energy loss, with increasing the bottom slope the energy loss is increased.

Figure 7 presents the effect of the hump angle 0 on the relative energy (efficiency) $E_{d} / E_{u}$ at different relative height $h / b$ for bottom slope of $0.0,0.01,0.02$ and 0.025 respectively. It is observed that the effect of $\theta$ on $E_{d} / E_{u}$ is significant. The $E_{d} / E_{u}$ decreases non-linearly with the increase of hump angle $\theta$. Also, the higher the $h / b$, the lower the efficiency $E_{d} / E_{u}$ which proves that the increasing $\mathrm{f} \mathrm{h} / \mathrm{b}$ has decreasing effect on efficiency $E_{d} / E_{u}$. The efficiency is the least value for $h / b=0.6$ and a maximum value for $h / b=0.1$. The rate of decrease of $E_{d} / E_{u}$ is relatively small up to $h / b=0.3$. The rate of decrease in the efficiency, Fig.7, is almost the same between the relative height 0.1 and 0.2 , and 0.2 and 0.3 , and 0.3 and 0.4 . It decreases to about 3 times between 0.4 and 0.5 and almost 4 times between 0.5 and 0.6 as compared to the decrease in efficiency $E_{d} / E_{u}$ between the relative height 0.1 to 0.2 . As the hump angle $\theta$ increases up to $50^{\circ}$ the rate of decrease in the efficiency $E_{d} / E_{u}$ is relatively high for all the relative heights $h / b$, being very high for $\mathrm{h} / \mathrm{b}$ of 0.6 . Above $\theta=50^{\circ}$ the decrease in the efficiency is much slower. Fig.8 shows the variation of upstream Froude number $F_{u}$ with the efficiency $E_{d} / E_{u}$ for different relative heights $h / b$ for $S_{o}$ of $0.0,0.01,0.02$ and 0.025 respectively at a fixed hump angle $\theta$ of $15^{\circ}$. From the figure the family of curves are similar hyperbolas of a higher order according to Eq.(5). At the value of $F_{u}$, the values of efficiency increasing with the decreasing value of relative height $\mathrm{h} / \mathrm{b}$. Also, with the same value of $h / b$, the value of $E_{d} / E_{u}$ increases with decreasing value of the upstream Froude number $\mathrm{F}_{\mathrm{u}}$. 
Measurements were made for various flow conditions. However, only representative results are presented here. The turbulence intensity components and steamwise and vertical mean velocity components are non-dimensionalized by the stream wise free stream velocity in $\mathrm{x}$-direction $\mathrm{U}_{\mathrm{o}}$. The water depth is non-dimensionalized by the stream wise free stream water depth $\mathrm{Y}_{\mathrm{o}}$. Turbulence at the wall was construed to be turbulence at a very location from the wall of the order of $1 \mathrm{~mm}$ as observed in laser Doppler. Anemometry (LDA) experimentation, and not at the wall itself peruse. At the boundary velocity and turbulence are zero. Fig. 9 shows the stream wise mean velocity profiles $\overline{\mathrm{u}} / \mathrm{U}_{\mathrm{o}}$ in the inclined hump with angle of variation $\theta$ of $15^{\circ}$ and $30^{\circ}$ at different locations. The stream wise mean velocity $\overline{\mathrm{u}} / \mathrm{U}_{\mathrm{o}}$ varies considerably according to the inclined hump angle $\theta$ and the flow conditions. The flow acceleration is seen to be maximum in the case of the $30^{\circ}$ inclined hump. Interestingly, the $15^{\circ}$ inclined hump not only reduce the flow acceleration with their gradients, but also influence the various effects close to the channel bed since wall shear stress deduced from the velocity of the very first point from the surface, seems to vary with the geometry. The wall shear stress of the inclined hump first increases when gradient is made $\theta=30^{\circ}$ and then it decreases when the gradient is further changed to $\theta=15^{\circ}$. Such reduction in the wall shear stress is a desired result and would be expected to reduce the energy loss. It can be seen that with decreasing hump inclination, the maximum negative (counter stream wise) velocities in the recirculation zone are reduced. In the external flow over the separation bubble, the maximum positive velocities are reduced as well for flatted hump. For flatter humps, the maximum mean velocities $\mathrm{u}^{+}$max. moves toward the middle of the channel behind to hump edge. With increasing angle $\theta$ the velocity profiles become more and more asymmetric and velocity gradient $(\mathrm{du} / \mathrm{dy})$ in the shear layer is growing. Reversal flow could be observed for hump angle $\theta=30^{\circ}$ as shown in Fig.9 at the locations $\mathrm{x} / \mathrm{h}$ of 1 and 2 , as was observed by dye injection.

Root mean square (RMS) values of stream wise and vertical components of turbulence intensity ( $u^{\prime}$ and $v^{\prime}$ ) carried out nondimensional with respect to the stream wise mean free stream velocity $U_{0}$. Figs. 10 and 11 show steamwise and vertical turbulence profiles $\mathrm{u}^{\prime} / \mathrm{U}_{\mathrm{o}}$ and $\mathrm{v}^{`} / \mathrm{U}_{\mathrm{o}}$ as a function of dimensionless channel depth $\mathrm{Y} / \mathrm{Y}_{\mathrm{o}}$ of the inclined hump for $\theta=15^{\circ}$ and $30^{\circ}$ for relative heights $\mathrm{h} / \mathrm{b}$ of 0.3 and 0.5 at different locations which are measure of fluctuations about the respective mean velocity shown in Fig. 9. The conditions of the flow at the inlet of the inclined hump cause unidirectional distortion of the fluid elements which may be expected to produce nonhomogeneous and anisotropic turbulence. Under the action of dynamics process, the turbulence was produced to some degree all over the field. The stream wise and vertical turbulence intensities $u^{`} / \mathrm{U}_{\mathrm{o}}$ and $\mathrm{v}^{`} / \mathrm{U}_{\mathrm{o}}$ grow rapidly after the flow separation and is spreading in all directions further downstream. An increase of the inclination angle from $15^{\circ}$ to $30^{\circ}$ and relative height form 0.3 to 0.5 do increase enormously the turbulence intensities after the hump edge. In the wall region defined by $\mathrm{Y} / \mathrm{Y}_{\mathrm{o}}<0.2$ the turbulence intensities $\mathrm{u} / \mathrm{U}_{\mathrm{o}}$ and $v^{`} / \mathrm{U}_{\mathrm{o}}$ have substantially small magnitude closer to the wall. With increasing distance from the boundary, the turbulence intensities $\mathrm{u}^{\prime} / \mathrm{U}_{\mathrm{o}}$ and $\mathrm{v}^{`} / \mathrm{U}_{\mathrm{o}}$ increase in wall region tending towards an maximum in the intermediate region (core region) defined by $0.2 \leq \mathrm{Y} / \mathrm{Y}_{\mathrm{o}} \leq 0.6$, where is the location of the maximum value of turbulence, reaching a lower value in the free surface region defined by $\mathrm{Y} / \mathrm{Y}_{\mathrm{o}}>0.6$ subsequently. It has been observed during this experimentation that, surface waves play an important role in the turbulence production. As a comprehensive observation, it was noted that, the stream wise and vertical turbulence intensities $\mathrm{u}^{\prime} / \mathrm{U}_{\mathrm{o}}$ and $\mathrm{v}^{\prime} / \mathrm{U}_{\mathrm{o}}$ for $30^{\circ}$ hump angle flow were always greater than that for $15^{\circ}$ hump angle flow $\mathrm{x} / \mathrm{h}>30$ the maximum turbulence intensely was reduced almost to the same level of the stream wise free stream turbulence intensity.

Corresponding to the stream wise mean velocity profiles Fig.9, measurements of vertical mean velocity $\bar{v} / \mathrm{U}_{\mathrm{o}}$ were conducted for inclined hump of $\theta=15^{\circ}$ and $30^{\circ}$ for relative height $h / b$ of 0.3 at the same flow conditions and locations at which the stream wise mean velocities were measured. Fig. 12 presents the profiles of vertical mean velocity distribution $\bar{v} / \mathrm{U}_{\mathrm{o}}$ at various locations. The profile of $\bar{v} / U_{0}$ assumes both positive and negative values at the same section and hence the zero value at some intermediate locations. This nature of variation, viz., change from positive to negative magnitude and vice versa occurred almost at all sections. The zero magnitude of vertical velocity component $\bar{v} / \mathrm{U}_{\mathrm{o}}$, occurs at more than one point at several locations. The magnitude of $\bar{v} / \mathrm{U}_{\mathrm{o}}$ increases steadily from the entrance section, the magnitude gradually decreases reaching small value at the farthest downstream of $x / h=30$. At exact entrance location, velocity $\bar{v} / U_{0}$ was negative all along the vertical height. This observations may be attributed to the expanding velocity field and diversion of flow at the hump corner.

The observation of the multiplicity of null point to the three dimensional interaction between the entrance flow to the hump almost with negative vertical velocity component. The influence of hump itself along with the bed impeding the downward component of velocity. This complex interaction would influence the flow pattern giving rise to multiplicity null point. In Fig.13, the stream wise $\overline{\mathrm{u}} / \mathrm{U}_{\mathrm{o}}$ velocity profiles in a channel cross section are plotted exemplarily for six different hump angles $\theta$ of $10^{\circ}, 15^{\circ}, 20^{\circ}, 30^{\circ}, 45^{\circ}$ and $90^{\circ}$ at channel location $x / b=3$. The described changes in the velocity data with decreasing hump angle $\theta$ could be seen. Smaller positive mean velocities in the external flow and the smaller negative velocities in the recirculation zone reduce the dimensions of the separation bubbles for flattened hump angles. The maximum negative stream wise velocity $\overline{\mathrm{u}}_{\max } / \mathrm{U}_{\mathrm{o}}$, is shown in Fig. 14 for different hump angle variations $\theta$ of $10^{\circ}, 15^{\circ}, 20^{\circ}, 30^{\circ}$ an $45^{\circ}$. The maximum of $\overline{\mathrm{u}}_{\mathrm{max}} / \mathrm{U}_{\mathrm{o}}$ is registered for all hump inclinations 
always in the middle of the separation zones. For $\theta=30^{\circ}$ and $45^{\circ}$ the peak of the maximum counter stream wise velocities. Also, it could be seen that steeper inclination angles result the higher maximum negative counter stream wise velocities $\overline{\mathrm{u}}_{\mathrm{max}} / \mathrm{U}_{\mathrm{o}}$ in the recirculation regime and the rotating mass flux of the total through is growing in the range between $20^{\circ}$ and $45^{\circ}$.

In Fig. 15 normalized turbulent profiles as shown exemplarity for different hump angles at $\mathrm{x} / \mathrm{b}=3$. It could be seen that hump angle variations $\theta<20^{\circ}$ result in much lower turbulence data than a $90^{\circ}$ hump flow under same conditions. Fig. 16 depicts the variations of maximum stream wise turbulence intensities $\mathrm{u}_{\max } / \mathrm{U}_{\mathrm{o}}$ in cross section as a function of hump angle $\theta$ at different positions of the hump. Turbulence $\mathrm{u}_{\max }^{\prime} / \mathrm{U}_{\mathrm{o}}$ rises rapidly to reach maxima with subsequent monotonous decrease with increasing the hump angle. Generally, the maximum turbulence intensities occur almost at the range of hump angles $\theta$ of $\left(25^{\circ}-35^{\circ}\right)$ at the different locations. Clearly, the trend of maximum stream wise turbulence intensities $u^{\prime}{ }_{\max } / \mathrm{U}_{\mathrm{o}}$ variation were quite similar in all different locations. It may be concluded that, beyond specific value of $\theta=30^{\circ}, \mathrm{u}_{\text {max }}{ }^{\prime} / \mathrm{U}_{\mathrm{o}}$ values were always higher in the case of cross section $\mathrm{x} / \mathrm{b}=4$ and lower for cross section $\mathrm{x} / \mathrm{b}=1$.

\section{CONCLUSIONS}

The conclusions arising out of this study can be summarized as follows:

Form the evidence of the variation of the energy los $\Delta \mathrm{E} / \mathrm{E}_{\mathrm{u}}$ with the range of the hump angle $\theta$. It could be concluded that the loss of energy increases rapidly up to hump angle $\theta$ of $45^{\circ}$. But above this angle $\theta=45^{\circ}$ the effect of the boundary is insignificant and with decreasing hump angle $\theta$, the energy loss decreases. The energy loss is quite high if the relative height $\mathrm{h} / \mathrm{b}>0.3$. Thus, $\theta=45^{\circ}$ appears to be critical defining a border value between the maximum loss of energy and the value up to which energy loss increases rapidly as hump angle $\theta$ increases from $0^{\circ}$ to $45^{\circ}$. The results indicate that, the most significant in energy loss occur with hump angle in the range less than $45^{\circ}$. Also, the energy loss increases with increasing values of upstream Froude number $F_{u}$, relative height $h / b$ and bottom slope $S_{0}$. Then, the hump angle, upstream Froude number and bottom slope have major effect on the energy loss. Set of equations of energy loss are presented in terms of the initial Froude number and relative water depth. The stream wise and vertical turbulence intensities $\mathrm{u}^{`} / \mathrm{U}_{\mathrm{o}}$ and $\mathrm{v}^{`} / \mathrm{U}_{\mathrm{o}}$ along the flow depth were lower at the bed in the wall region defined by $\mathrm{Y} / \mathrm{Y}_{\mathrm{o}}<0.2$ and the free sufface region defined by $\mathrm{Y} / \mathrm{Y}_{\mathrm{o}} \geq 0.6$ and the minimum values of $\mathrm{u}^{\prime} / \mathrm{U}_{\mathrm{o}}$ and $\mathrm{v}^{`} / \mathrm{U}_{\mathrm{o}}$ occur at the same location of the profiles, either close to the bed or close to the free surface. The maximum of $u^{\prime} / U_{o}$ and $v^{`} / U_{o}$ being located approximately at the same location of the profiles in the intermediate core region defined by $0.2<\mathrm{Y} / \mathrm{Y}_{\mathrm{o}}<0.6$. The $\mathrm{u}^{\prime} / \mathrm{U}_{\mathrm{o}}$ and $v^{\prime} / \mathrm{U}_{\mathrm{o}}$ increase with increasing relative height $\mathrm{h} / \mathrm{b}$. As a comprehensive observation, it was noted that, $\mathrm{u}^{\prime} / \mathrm{U}_{\mathrm{o}}$ was always greater compared to the $v^{`} / U_{0}$ where the trend of variation being similar. After $h / b>30$ the maximum turbulence intensity was reduced almost to the same level of the stream wise free stream turbulence intensity. It can be concluded that, hump angles $\leq 20^{\circ}$ result in much lower turbulence, wheras $20^{\circ}<\theta<30^{\circ}$ lead to higher turbulence compared with a $\theta=90^{\circ}$ flow. Also, it may concluded that, beyond specific value of $\theta=30^{\circ}$, turbulence intensities values are higher in the case of cross section $\mathrm{x} / \mathrm{b}=4$ and lower for cross section $\mathrm{x} / \mathrm{b}=1.0$.

\section{NOMECLATURE:}

$\overline{\mathrm{u}}$ Stream wise mean velocity in $\mathrm{x}$-direction,

$\mathrm{U}_{\mathrm{o}}$ Stream wise mean free steam, velocity averaged over the cross section.

ù Stream wise component of turbulence intensity in $\mathrm{x}$ - direction (RMS),

$\overline{\mathrm{V}}$ Vertical mean velocity in y-direction,

v́ Vertical component of turbulence intensity in $\mathrm{y}$ - direction (RMS),

$\mathrm{x}$ Longitudinal axis along channel length,

y Transverse axis along channel height,

$\mathrm{z}$ Transverse axis along channel width,

Q Flow discharge,

RMS Root mean square.

\section{REFERENCES}

[1] Antoniou, J., and Bergeles, G., (1998), "Development of the Reathachent Flow Behind Surface Mounted Two Dimensional Prisms", ASCE J. of Fluids Engg. Vol. 110, Pp.127-133.

[2] Attia, M.I. and Josh, S.G., (1995) "Experimental Studies of Turbulent Flows in sudden and Gradual Open Channel Transitions Using laser Doppler Velocimetry" Proc. Of $22^{\text {nd }}$ National Conf. on Fluid Mech. and Fluid Power (FMFP), Editors, V. Ganesan, Indian Inst. Of Tech., Mardras, India, Pp. 139-147, 1315 December.

[3] Amino, R.S., and Goel, P., (1985) "Computations of Turbulent Flow Deyond Baclcward Facing Steps Using Reynolds Stress Closure", AIAA J., Vol. 23, No. 23, No.9, Pp. 1356-1361.

[4] Chow, V.T., (1959) "Open Channel Hdroulics", Mc Graw Hill Book Co., New York, Pp. 461-468.

[5] Etheridge, D.W., and Kemp, P.H., (1978), "Measurements of Turbulent Flow Downstream of a Rearward Facing Step", Fluid Mech. No.3.

[6] Formica, G., (1955), "Preliminary Test on Head Losser in Channels due to Cross Sectional Changes," L'Energia Electrical, Milano, Vol.32, No.7, Pp554-568, July.

[7] Garde, H., (1993), "The Turblent Flow Models in Open Channel Flows" Monograp, A.S. Balkema Publishers, New Road, V.T 08079, New Delhi, India.

[8] Nezu, I., and Nakagawa, (1995), "Experimental Investigation on Turbulent Structue of Backward 
Facing Step Flow in an Open Channel", J. of Hydr. Research, Vol.25, No.1.

[9] Kironoto, B.A., and Gard, W.H., (1994), “Turbulence Characteristics in Rough Open Channel Flow", Proc. Inst. Civ. Engg. Water, Maritime Energy., 98.

[10] Melelland, S., Ashworth, P., Best, J., and Livesey, J., (1999), "Turbulence and Secondary Flow over sediment Srips in Weakly Bimodal Bed Material", J. SAecondar Flows, 125 (5), 463-473.

[11] Nzu, I., and Rodi, W., (1986), "Open Channel Flow Measurement with a Laser Dopler Velocimetry", J. Hydraulic Eng. ASCE, 112, Pp.335-355.

[12] Nezu, I., and Nakagawa, H., (1993), “Turbulence in Open Channel Flow", IAHR-Monograph, A.A.Balkma Publishers, Old Post Road, Brookfield, VT5036, USA.

[13] Nakagawa, H., and Nezu, I., (1987), "Experimental Investigation on Turbulent Structure of Back Facing Step Flow in an Open Channel", J. Hydraulic Research, IAHR, 25, Pp. 67-88.

[14] Nandana Vittal, (1978), "Direct Soluations to problems of Open Channel Transitions", Proc. Of the ASCE, Vol. 104, No.Hy11.
[15] Ruck, B., and Makiola, B., (1990), "Flow over a single Sided Backward Facing Step with Step Angle Variations", Proc. $3^{\text {rd }}$ Int. Conf. of Laser Anemometry, BHRA, Springer Verlag, UK, Pp.369-378.

[16] Rodi, W., (1993), "Turbulence Models and their Application in Hydraulics", IAHR Monograh, A.A. Balkema Publishers, Old Post Road field, VT 05036, USA.

[17] Song, T., and Chinew, Y., (2001), "Turbulence Measurement in Non uniform Open Channel Flow Using Acoustic Doppler Velocimeter (ADV)", J.Eng.Mech., 127(3), 219-231.

[18] Sukhodolov, A.,Thiele, M., and Bungartz, H., (1998), "Turbulence Structure in a River Reach with Sand Beds", Water Resour. Res., 34(5), 1317-1334.

[19] Vitaal, N., and Chirangeevi, V.V., (1983), "Open Channel Transitions: Rational Methods of Design", J. of Hyd. Div., ASCE, Vol. 109, No.1, Pp 99-115. 


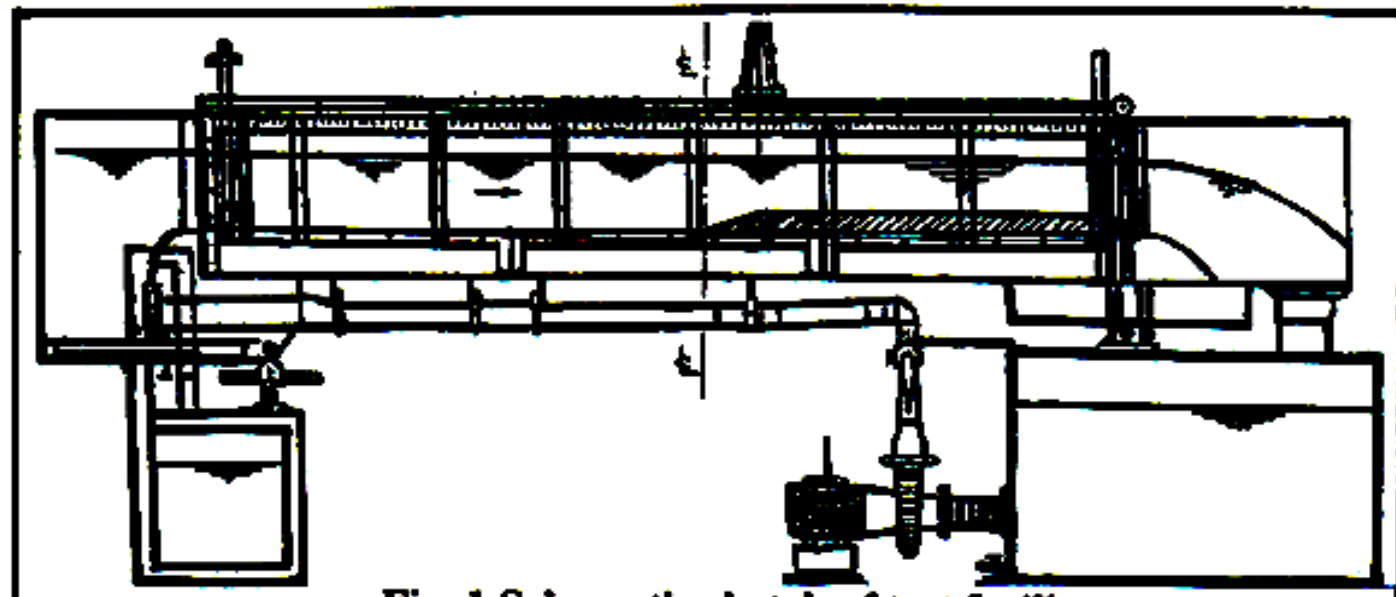

Fig. 1 Sehematic sketch of test facility.

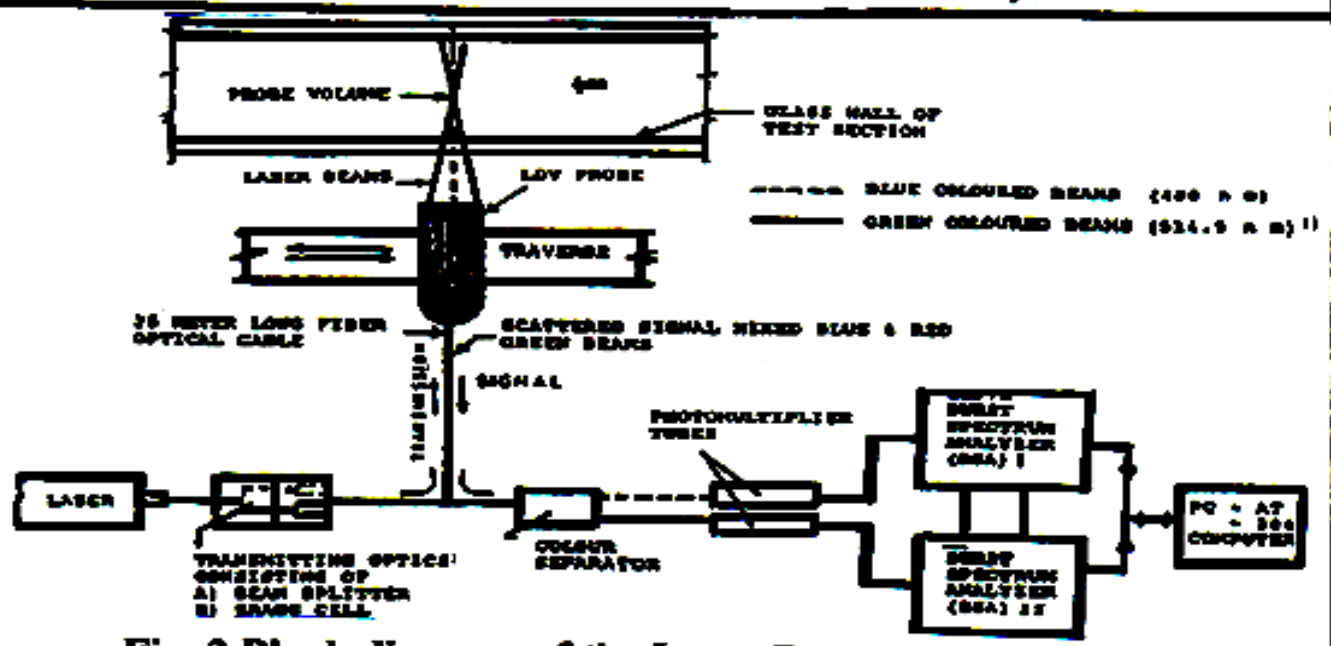

Fig. 2 Block diagram of the Laser Doppler Velocimetry.

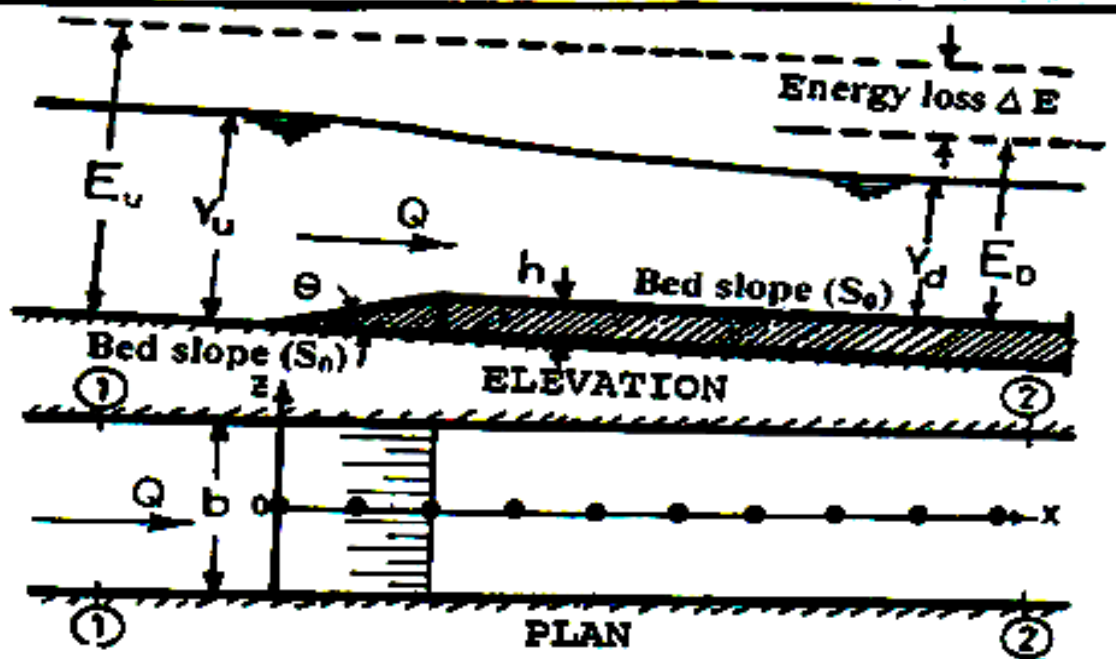

Fig. 3 Definition sketch showing the variables of the hump 

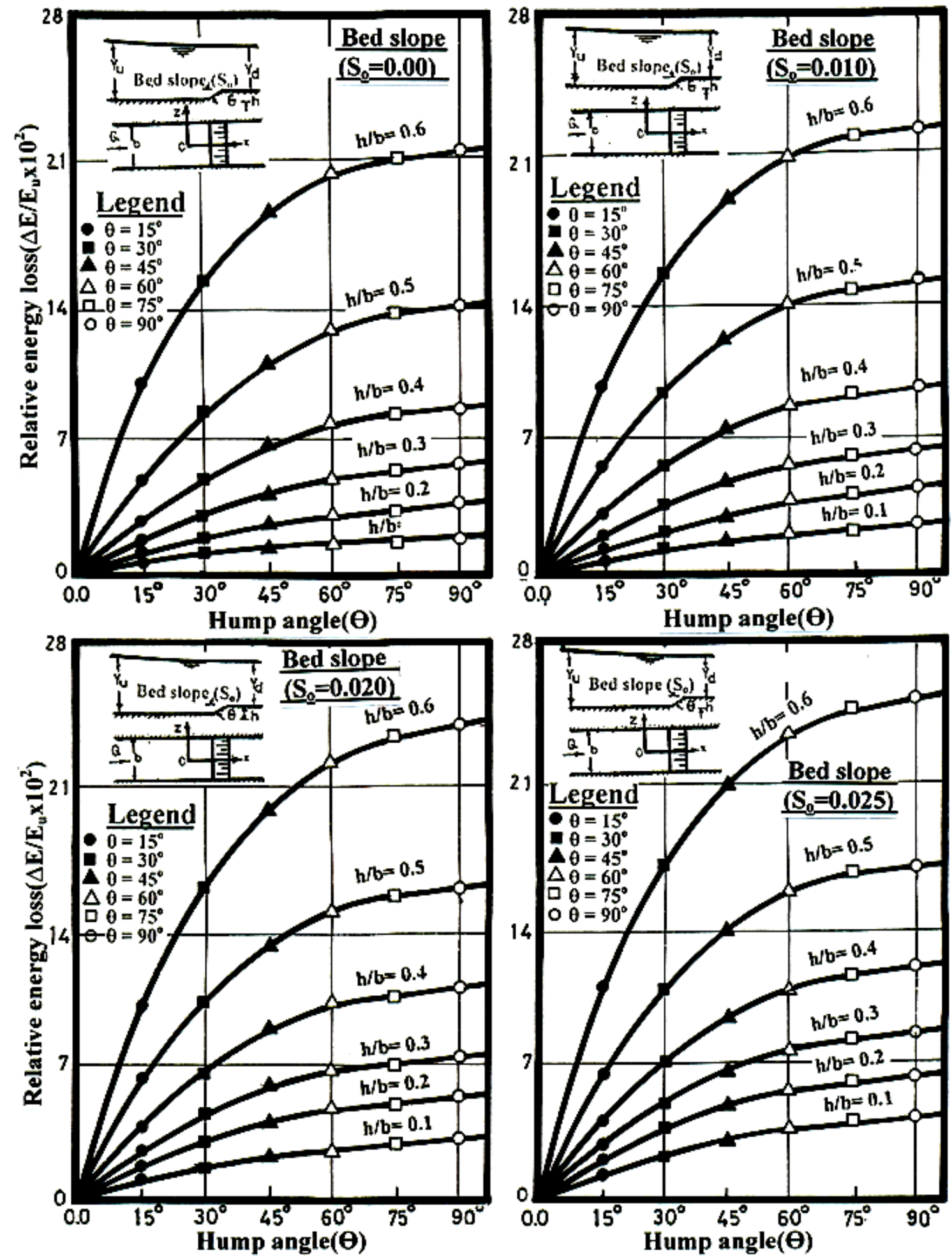

Fig.(4)Variation of hump angle $\Theta$ with relative energy loss $\Delta E / E_{u}$ for different relative height $h / b$ at different bed slope $S_{0}$. 

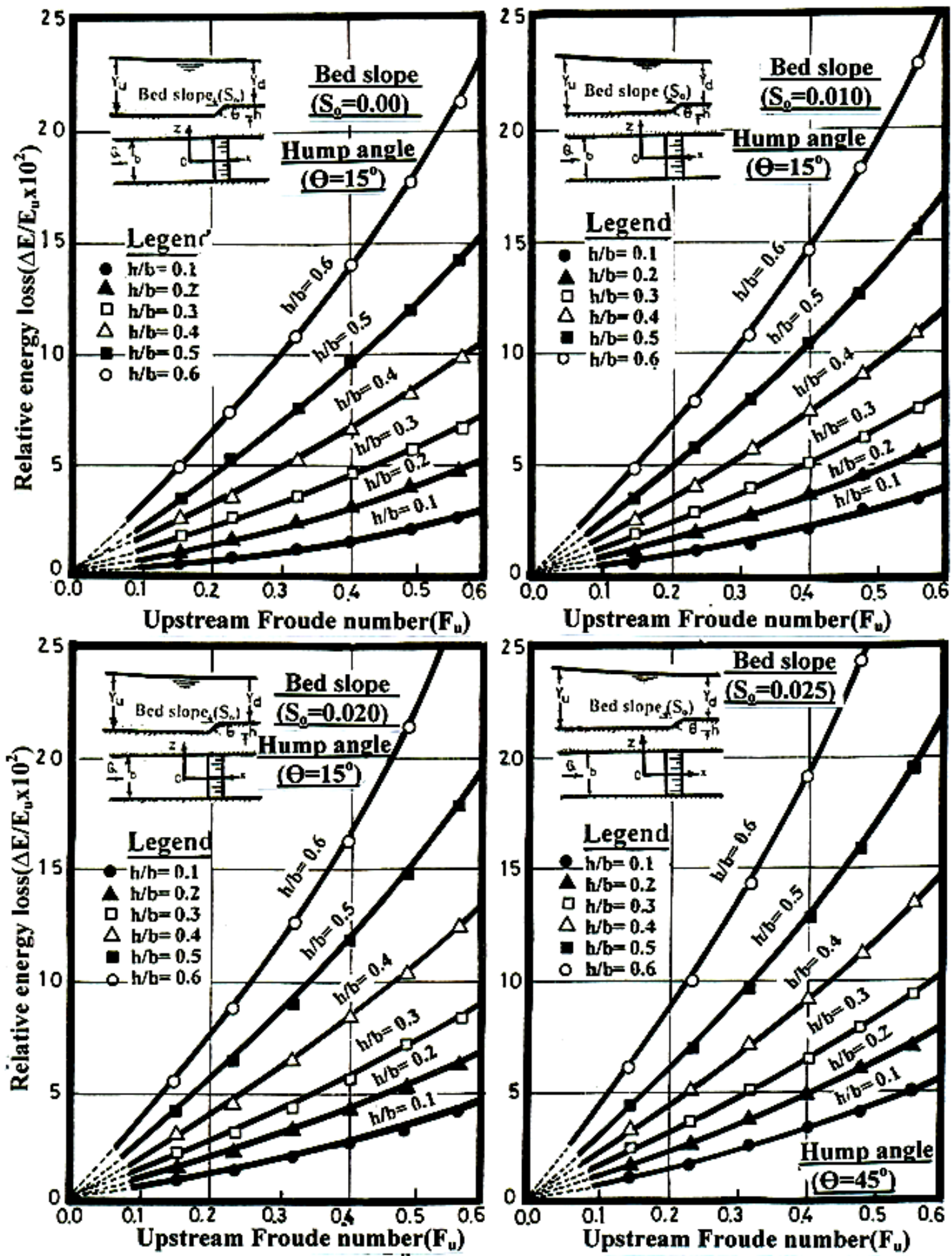

Fig.(5)Variation of upstream Froude number $F_{u}$ with relative energy loss $\Delta E / E_{u}$ for different relative height $h / b$ at different bed slope $S_{0}$ at fixed hump angle $\Theta=15^{\circ}$. 

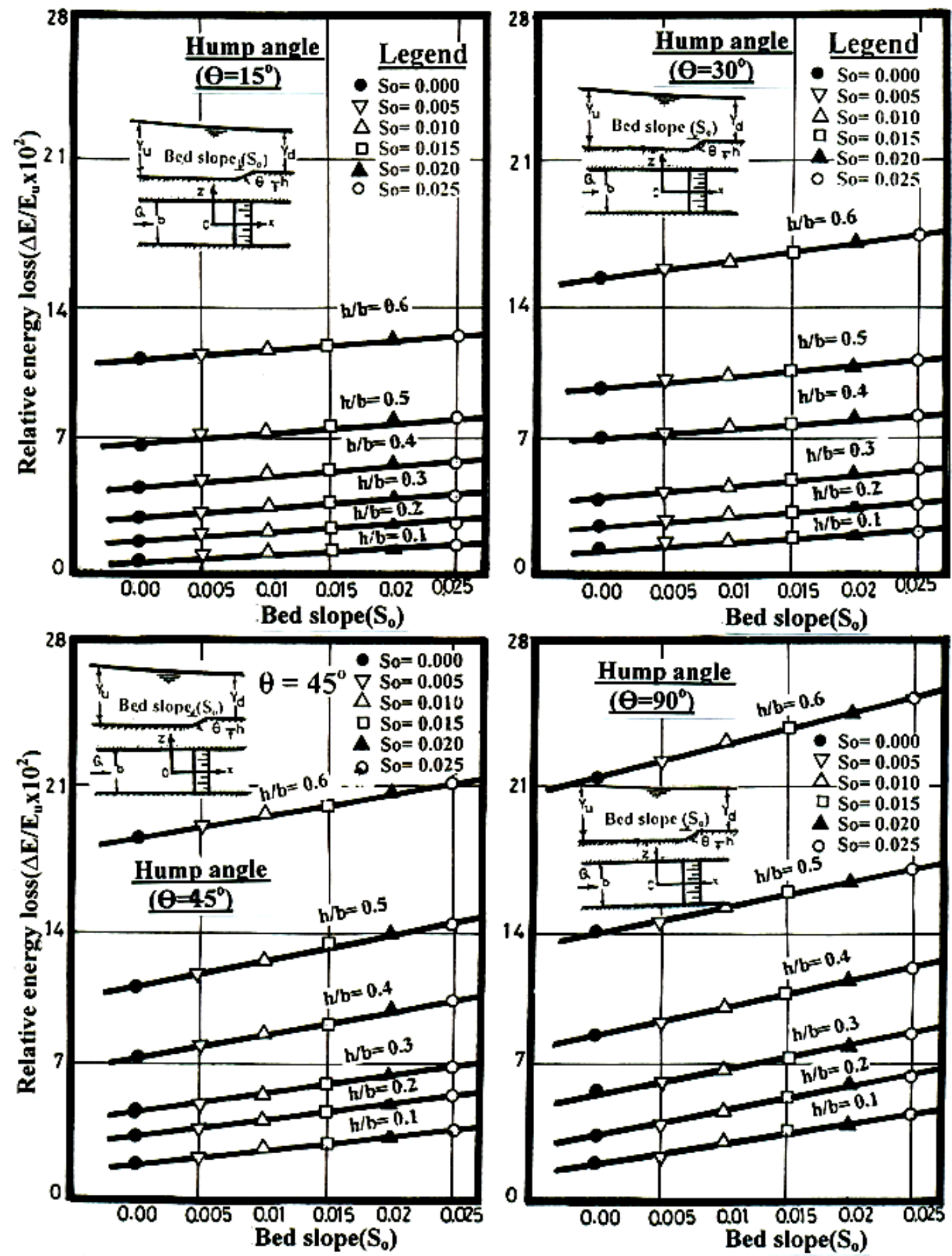

Fig.(6)Variation of bed slope $S_{0}$ with relative energy loss $\Delta E / E_{u}$ for different relative height $h / b$ at different hump angle $\theta$. 

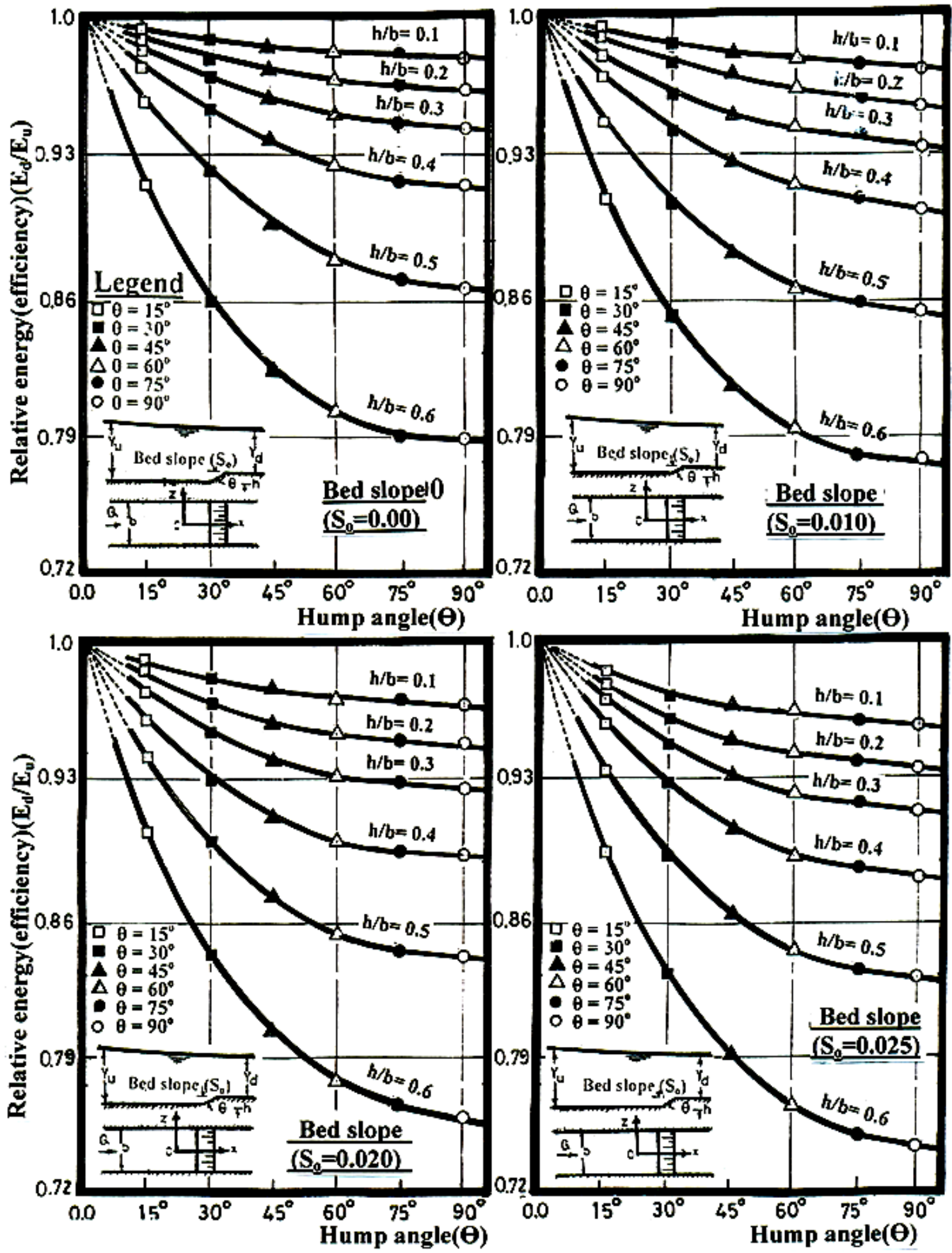

Fig.(7)Variation of hump angle $\Theta$ with relative energy(efficiency) $E_{d} / E_{u}$ for different relative height $h / b$ at different bed slope $S_{0}$ at fixed hump angle $\Theta=15^{\circ}$. 

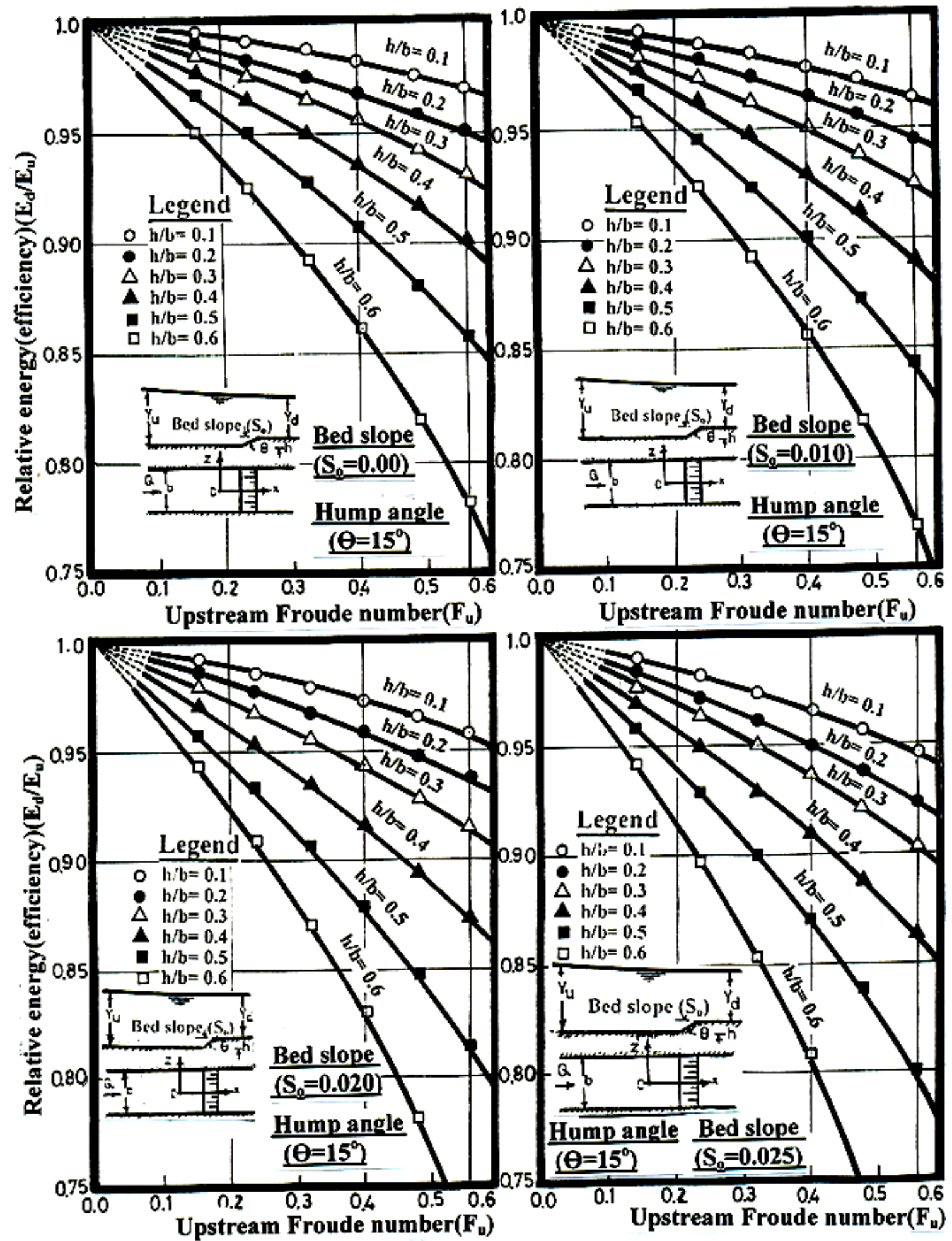

Fig.(8)Variation of upstream Froude number $F_{u}$ with relative energy(efficiency) $E_{d} / E_{u}$ for different relative height $h / b$ at different bed slope $S_{0}$ at fixed hump angle $\theta=15^{\circ}$. 

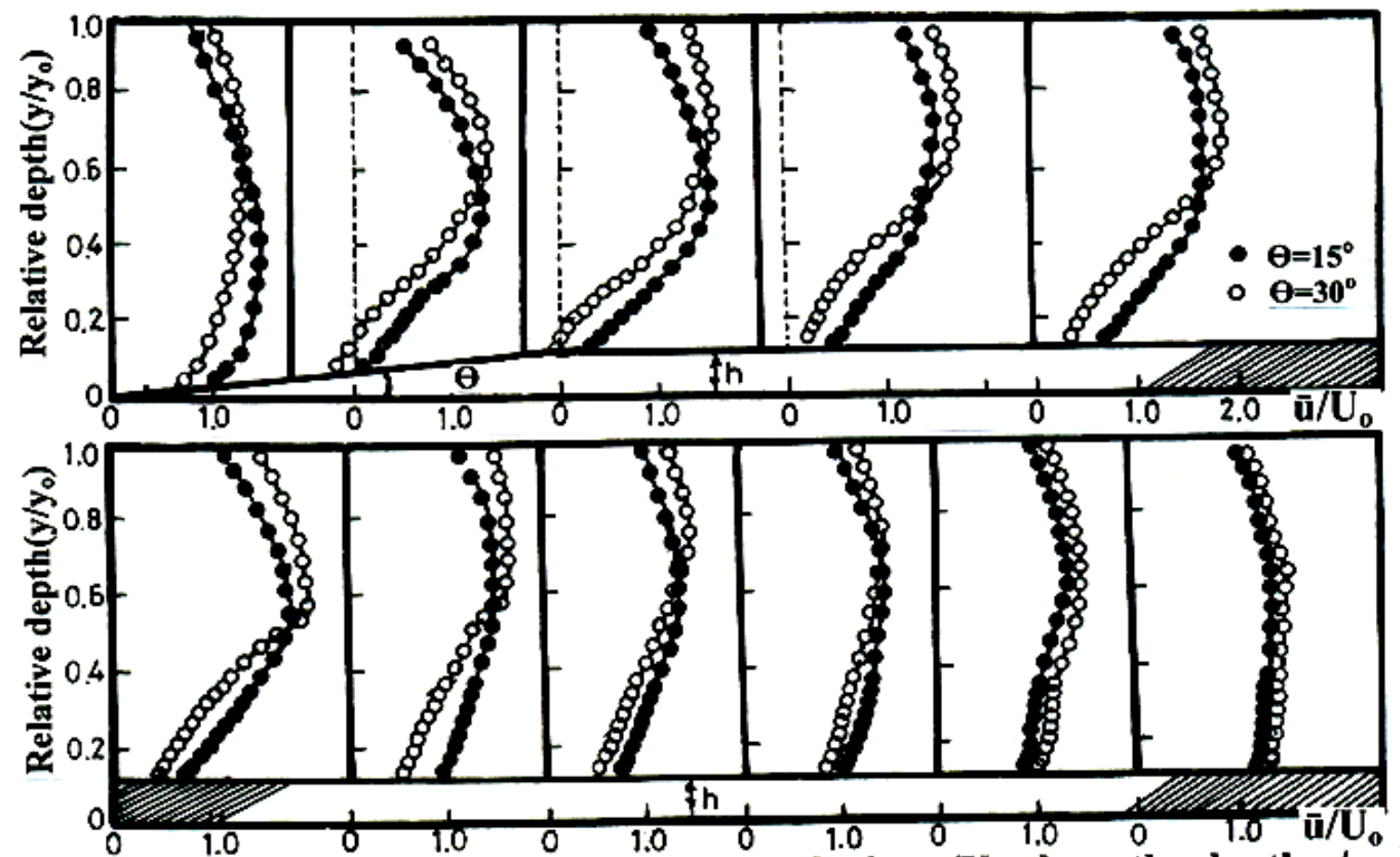

Fig.(9)Variation of streamwise mean velocity $\bar{u} / U_{0}$ along the depth $y / y_{0}$ at different cross sections at hump angle $\Theta=15^{\circ}$ and $30^{\circ}$ for $h / b=0.3$

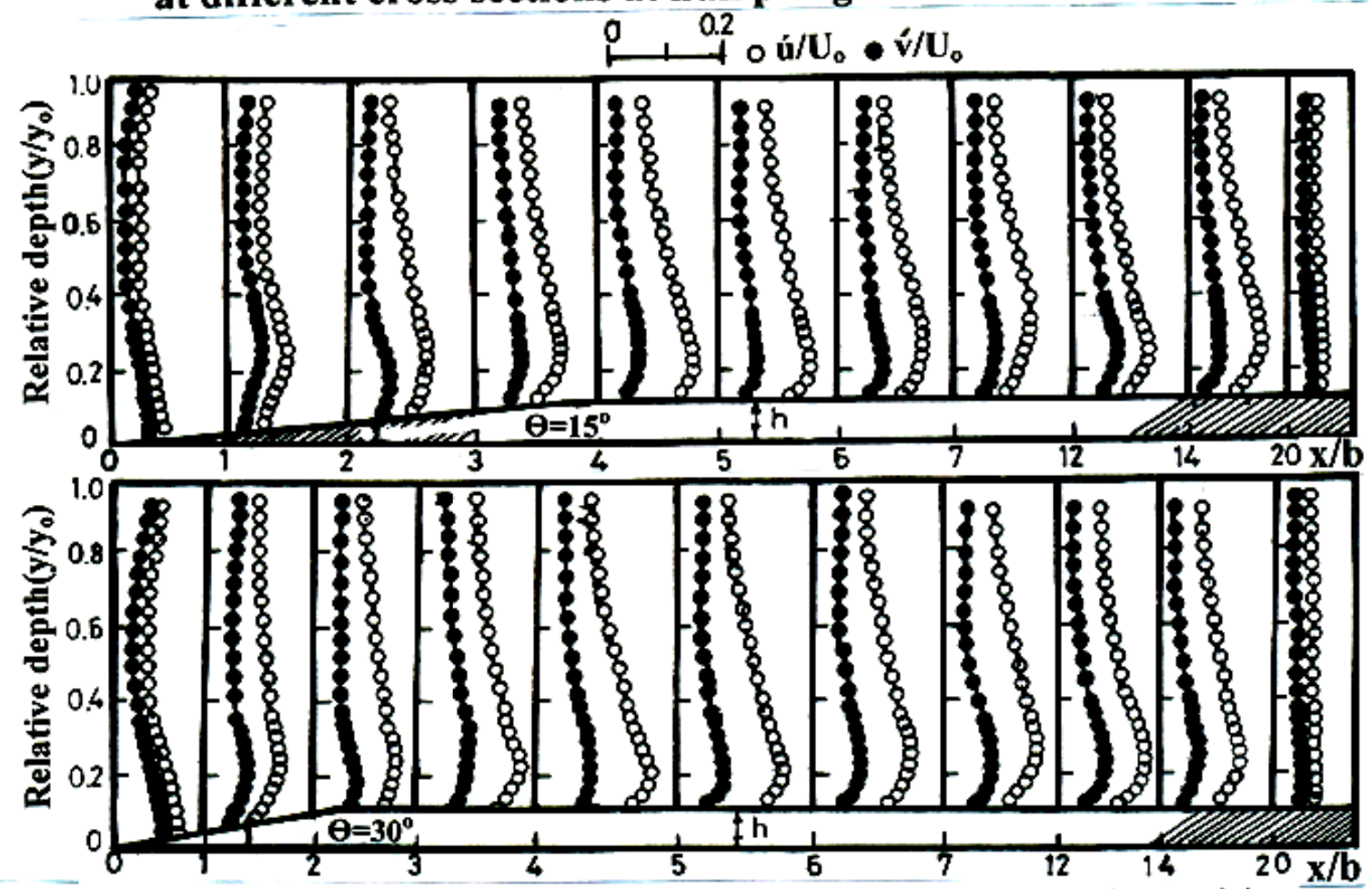

Fig.(10)Variation of streamwise and vertical turbulence intensities $\dot{u} / U_{0}$ and $v^{\prime} / U_{0}$ along the depth $y / y_{0}$ at different cross sections at hump angle $\Theta=15^{\circ}$ and $30^{\circ}$ for $h / b=0.5$. 


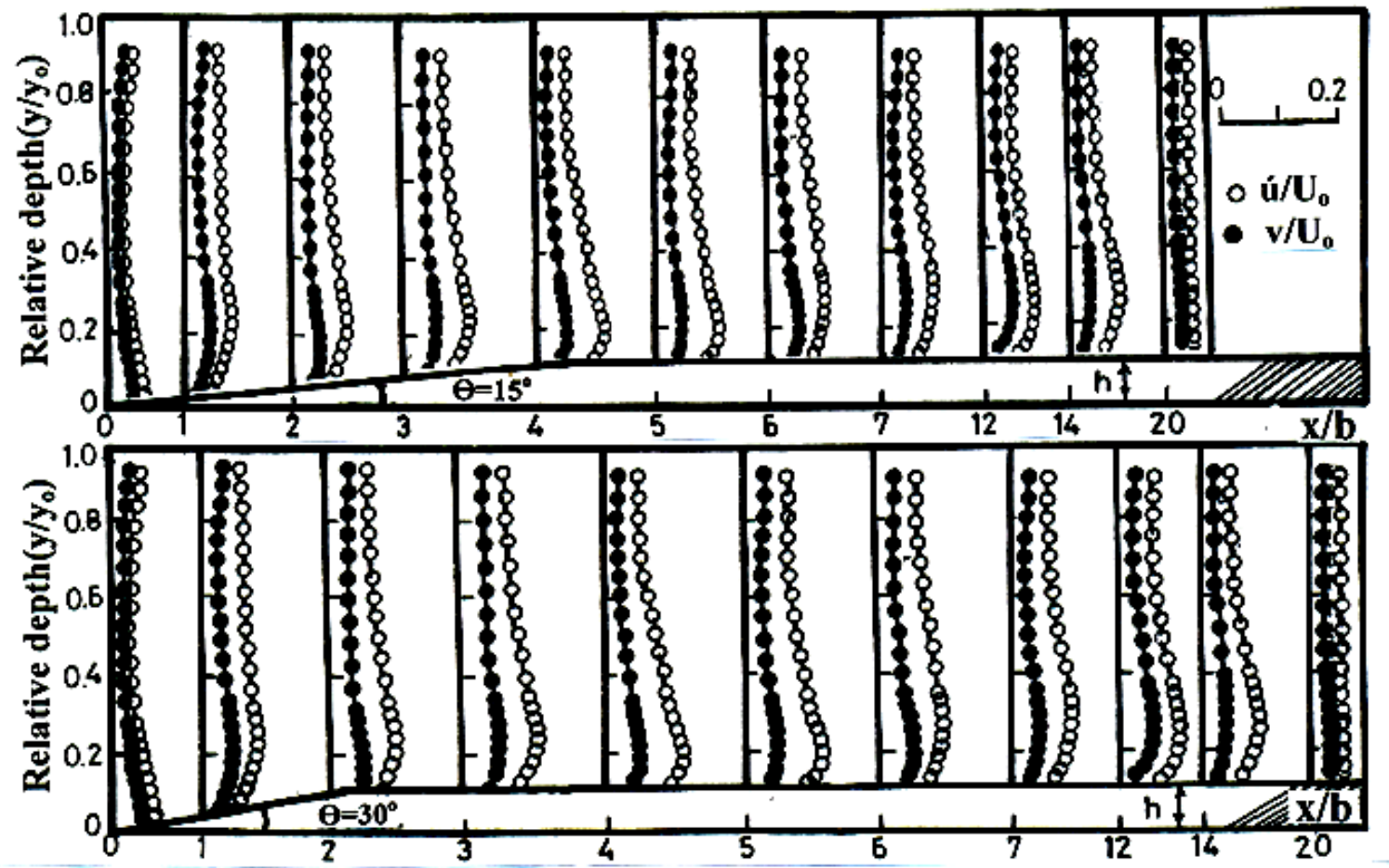

Fig.(11)Variation of streamwise and vertical turbulence intensities $u / U_{o}$ and $v^{\prime} / U_{0}$ along the depth $y / y_{0}$ at different cross sections at hump angle $\theta=15^{\circ}$ and $30^{\circ}$ for $h / b=0.3$.
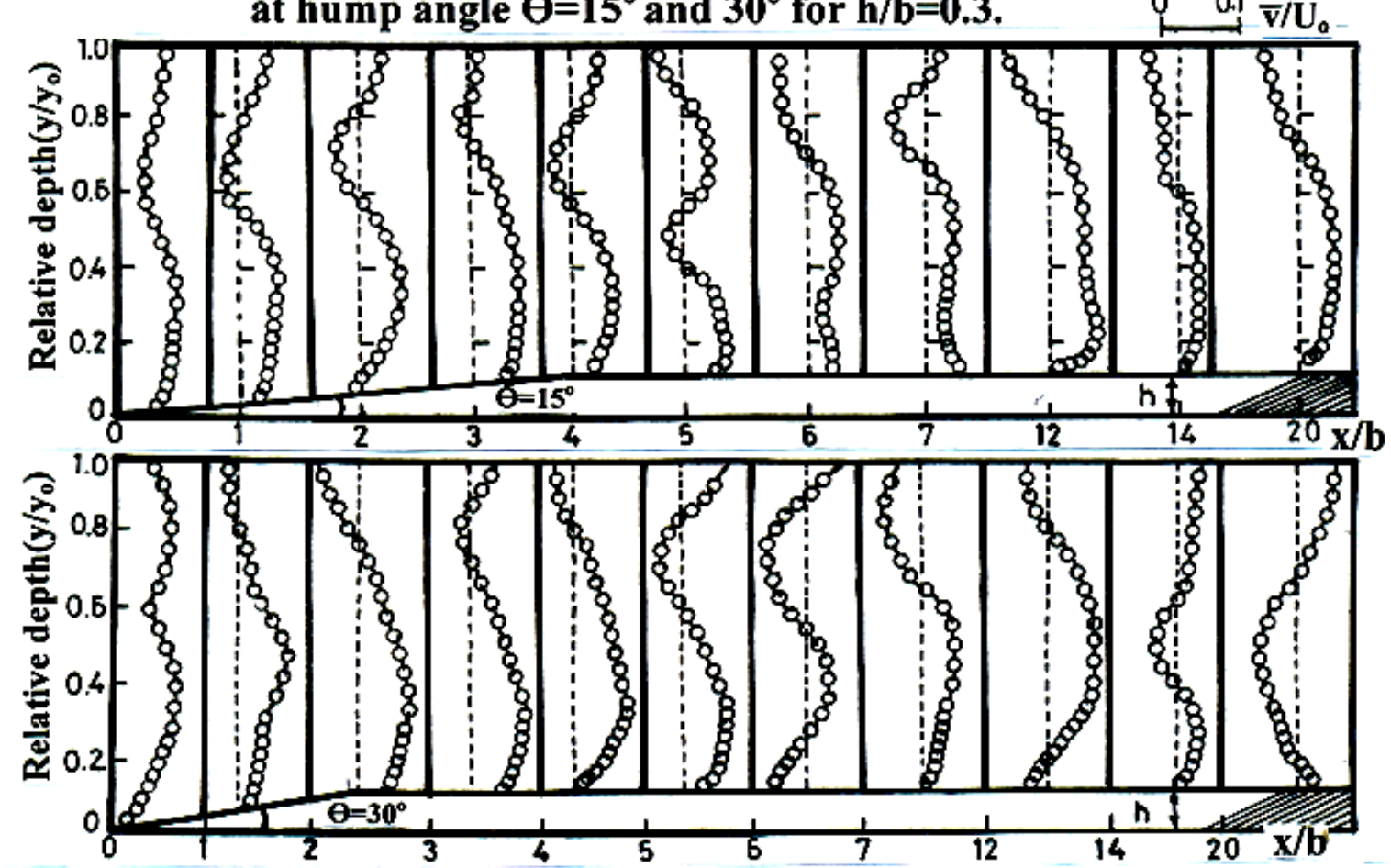

Fig.(12)Variation of vertical mean velocity $\bar{v} / U_{0}$ along the depth $y / y_{0}$ at different cross sections at humb angle $\Theta=15^{\circ}$ and $30^{\circ}$ for $h / h=0.3$. 

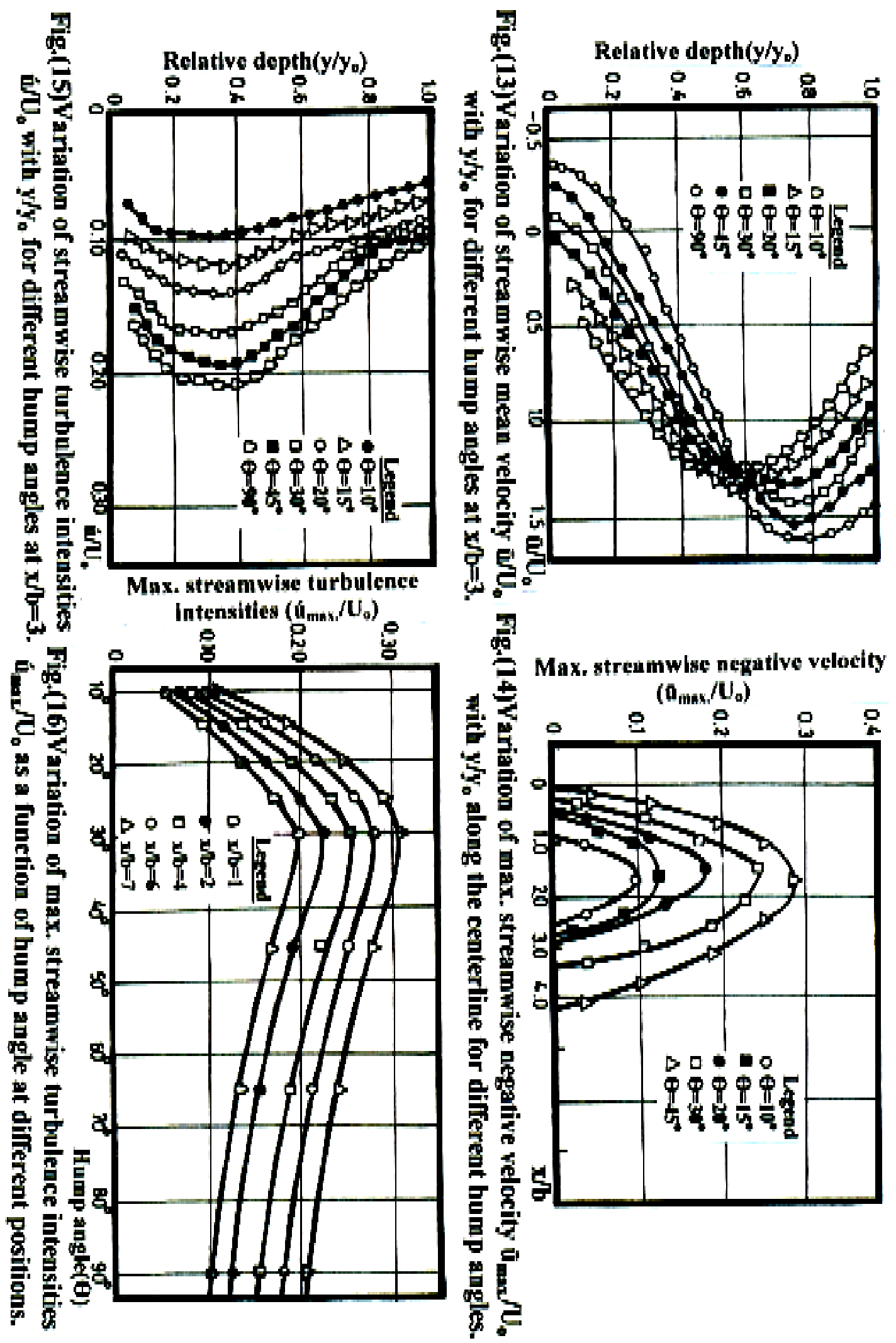